\title{
Antineutrophil cytoplasmic antibody-associated vasculitis, update on molecular pathogenesis, diagnosis, and treatment
}

This article was published in the following Dove Press journal: International Journal of Nephrology and Renovascular Disease

\author{
Farid Arman' \\ Marina Barsoum' \\ Umut Selamet' \\ Hania Shakeri ${ }^{1}$ \\ Olivia Wassef' \\ Mira Mikhail ${ }^{2}$ \\ Anjay Rastogi' \\ Ramy M Hanna'
}

'Department of Medicine, Division of Nephrology, UCLA David Geffen School of Medicine, Los Angeles, CA, USA; ${ }^{2}$ College of Biological Sciences, Biola University, La Mirada, CA, USA

Correspondence: Ramy M Hanna Department of Medicine, Division of Nephrology, University of California Los Angeles, 7-I55 Factor Building, 700 Tiverton Avenue, Los Angeles, CA 90095, USA

Email rhannamd8I@yahoo.com

\begin{abstract}
Circulating antineutrophil cytoplasmic antibodies (ANCAs) are the central pathogenic mechanism for a group of systemic and renal syndromes called the ANCA-associated vasculitis (AAV). The nomenclature has changed from eponymous labeling to granulomatosis with polyangiitis, eosinophilic granulomatosis with polyangiitis, and microscopic polyangiitis. These syndromes predominantly affect the pulmonary and renal systems. We also review the molecular pathology behind ANCAs and associated antigens and infections. Various clinical presentations, the multiple target organs affected, and diagnostic challenges involved in identifying these diseases are discussed. Treatment updates are also provided with regard to new studies and the now standard use of anti-CD-20 monoclonal antibodies as first-line therapy in all but the most aggressive presentations of this disease. Maintenance regimens and monitoring strategies for relapse of vasculitis and associated systemic complications are discussed.

Keywords: proteinuria, glomerulonephritis, ANCA associated vasculitis, rituximab, P-ANCA, C-ANCA
\end{abstract}

\section{Introduction}

Antineutrophil cytoplasmic antibody (ANCA) is the common thread in various diseases known as ANCA-associated vasculitis (AAV). They are generally one of two immunofluorescence patterns: peri-nuclear ANCA (P-ANCA) or cytoplasmic ANCA (C-ANCA). ${ }^{1}$ The two main antigens that these antibodies are directed against are proteinase 3 (anti-PR3) and myeloperoxidase (anti-MPO), with the anti-PR3 generally being associated with $\mathrm{C}$-ANCA and the anti-MPO being associated with P-ANCA. ${ }^{2}$

Classically, these syndromes were named eponymously. C-ANCA syndromes were named Wegener's granulomatosis, but this has been replaced in the lexicon with granulomatosis with polyangiitis (GPA). P-ANCA syndromes were named as Churg-Strauss disease which also known as eosinophilic granulomatosis with polyangiitis (EGPA), whereas microscopic polyangiitis has remained microscopic polyangiitis (MPA).

\section{Associations and epidemiology}

GPA is a C-ANCA pattern AAV with the vast majority of antibodies associated as antiPR3. However, a group of these cases (especially in Asian countries) are associated with P-ANCA rather than C-ANCA. It has generally been described as an idiopathic syndrome that tends to occur in elderly patients, and it has a cyclic pattern of occurrence, suggesting the influence of infection in triggering GPA. ${ }^{3}$ There have also been various studies correlating malignancy and GPA. ${ }^{4}$ ANCAs can also sometimes coexist with cryoglobulins 
and anti-glomerular basement membrane (anti-GBM) antibodies. Hepatitis $\mathrm{C}$ has also been associated with GPA, as well as MPA albeit rarely. ${ }^{5}$ Some medications have also been noted to induce AAV, and propylthiouracil (PTU) has been reported as a drug linked to both PR3 and MPO ANCA seropositivity (MPO-ANCA being more common). However, only small percentage of these patients develops clinical vasculitis. ${ }^{6}$

EGPA is an idiopathic allergic syndrome that is primarily associated with immunogenic antigen exposure (vaccinations, infections, medications, and foreign body exposures). ${ }^{7}$ MPA is generally a small vessel vasculitis that is generally idiopathic or infection related; it is pathologically related to polyarteritis nodosa (PAN), which is associated with hepatitis B. MPA is not as strongly related to hepatitis B as PAN, but cases of association with hepatitis $\mathrm{C}$ have also been reported. ${ }^{5}$

\section{Molecular pathology}

Some progress in understanding how GPA occurs has been gleaned from understanding the role of toll-like receptor 3 (TLR3) in the pathology of autoimmunity. The activation of this receptor has been previously implicated in immune complex glomerular disease and glomerulopathy due to viral infection and direct toxicity. ${ }^{8}$ Targets of ANCAs are typically intracellular proteins in granulocytes, and they include proteinase 3, myeloperoxidase, elastase, cathepsin $\mathrm{G}$, lactoferrin, and lysozyme. ${ }^{1,9}$ The P-ANCA and C-ANCA patterns correspond to anti-MPO and anti-PR3 with a high degree of sensitivity and specificity ( $97 \%$ and $80 \%$, respectively). ${ }^{1,2}$ Atypical ANCA patterns do exist, and they are noted in the literature as X-ANCA. ${ }^{1}$

New studies have also found a link between neutrophils and the antibody-mediated nature of AAV. Hewins et a ${ }^{10}$ suggested that IL-18 is upregulated in renal cells in patients with AAV. This likely suggests a role for this interleukin to prime neutrophils and initiate the autoimmune cascade that leads to the usually observed often necrotizing glomerulonephritis. ${ }^{10}$

\section{Clinical presentation}

AAV have traditionally been called pulmonary-renal syndromes due to their predilection for causing pulmonary hemorrhage and hematuria due to nephritic inflammation due to necrotizing crescentic glomerulonephritis. Sinus disease and otitis media in adults are also common features of GPA. ${ }^{11,12}$ EGPA tends to present with peripheral eosinophilia, asthma, and dermatologic manifestations. MPA, however, tends to be associated with only small vessel vasculitis (hence the name microscopic polyangiitis).

There are, however, copious examples of unusual presentations of AAV. Examples of cardiac arrhythmias and myocarditis have been reported as part of GPA syndromes. ${ }^{11}$ Epidemiological studies also showed a higher incidence of cardiac abnormalities in patients with AAV. ${ }^{13}$ Other case reports have noted gastrointestinal disease associated with AAV, including AAV mimicking surgical abdominal disease and inflammatory bowel disease. ${ }^{12}$

The most severe presenting signs indicating a higher acuity vasculitis with increased risk of mortality include the findings of pulmonary hemorrhage and dialysis requiring acute kidney injury on presentation. ${ }^{14}$ These findings are indicators of severe vasculitis that has a high risk for morbidity and mortality in GPA. Findings of a rapidly progressive glomerulonephritis picture regardless of the level of proteinuria should prompt an emergent biopsy and aggressive cytotoxic therapy if it is safe to use. ${ }^{14}$ The finding of anti-GBM antibody often augurs a poor outcome in AAV. ${ }^{15}$ The higher level of antibody, particularly anti-PR3, also seems to point to a poor outcome. ${ }^{16}$

Prompt diagnosis is usually made by urinary examination for sediments including red cell casts, a trend of inexorably worsening serum creatinine, finding of unexplained proteinuria, along with the correct clinical picture and accompanying serologies of AAV. The clinical criteria for the diagnosis of the three AAV discussed in this review, GPA, ${ }^{17,18}$ EGPA, ${ }^{7,19}$ and MPA, are listed in Table $1 .^{20}$

\section{Treatment regimens}

Traditional management of AAV had been the prompt use of pulse dose intravenous (IV) cyclophosphamide in patients who presented with hematuria and the usual nephritic picture of GPA. Older strategies such as use of intravenous immunoglobulin (IVIG) have fallen out of favor. ${ }^{21}$ The toxicities of cyclophosphamide therapy, including leukopenia, thrombocytopenia, hemorrhagic cystitis, infection, and malignancy, were magnified usually in the older group of patients who are prone to AAV. In 2010, Stone et $\mathrm{al}^{22}$ presented the findings of the Rituximab for ANCA-associated vasculitis (RAVE) trial, showing that rituximab treatment is not inferior to daily oral or IV pulse cyclophosphamide. The typical dosing of rituximab is $0.375 \mathrm{~g} / \mathrm{m}^{2}$ given weekly for 4 weeks, ${ }^{22,23}$ along with high-dose steroids to be tapered. The toxicity of steroid therapy will be discussed later.

It was thought that the more severe rapidly progressive forms of AAV especially GPA remain best treated with cyclophosphamide, pulse dose steroids, and plasmapheresis. ${ }^{24}$ This same aggressive approach is recommended in patients with pulmonary hemorrhage and patients who present with dialysis-requiring AKI as first presentation of their AAV, 
Table I Clinical criteria for GPA, E-GPA, and MPA

\begin{tabular}{|l|l|l|l|l|}
\hline $\begin{array}{l}\text { Type of } \\
\text { AAV }\end{array}$ & Clinical criteria & Associations & $\begin{array}{l}\text { PR3 } \\
\text { (C-ANCA) }^{\mathbf{a}}\end{array}$ & $\begin{array}{l}\text { MPO } \\
\text { (P-ANCA) }^{\mathbf{a}}\end{array}$ \\
\hline GPA & $\begin{array}{l}\text { EULAR: nose bleeds, nasal polyps, } \\
\text { hearing loss or reduction, cartilaginous } \\
\text { involvement, conjunctival injection, eye } \\
\text { pain, C-ANCA or PR3+, normal eosinophil } \\
\text { count, and granuloma on biopsy }\end{array}$ & $\begin{array}{l}\text { Malignancy, idiopathic, sinus } \\
\text { infections, hematuria, hemoptysis } \\
\text { due to pulmonary hemorrhage, and } \\
\text { rarely hepatitis C infection }\end{array}$ & + & - \\
\hline E-GPA & $\begin{array}{l}\text { Asthma, eosinophilia of }>10 \% \text { in peripheral } \\
\text { blood, paranasal sinusitis, pulmonary } \\
\text { infiltrates, extravascular eosinophils, and } \\
\text { mono or polyneuropathy }\end{array}$ & $\begin{array}{l}\text { Eosinophilia, asthma, pneumonia, } \\
\text { and neuropathy }\end{array}$ & - & + \\
\hline MPA & $\begin{array}{l}\text { Vasculitis, glomerulonephritis, and } \\
\text { P-ANCA (anti-MPO) predominant }\end{array}$ & $\begin{array}{l}\text { Hepatitis B is implicated with PAN, } \\
\text { the large vessel vasculitis form of } \\
\text { MPA. PAN causes aneurysms and } \\
\text { renal artery stenosis, and MPA is a } \\
\text { form that causes glomerular disease }\end{array}$ & - & + \\
\hline
\end{tabular}

Notes: ${ }^{a}$ What is represented here is the most common association between ANCA and vasculitis type. However, it is important to keep in mind that often there may be different associations.

Abbreviations: AAV, ANCA-associated vasculitis; C-ANCA, cytoplasmic antinuclear cytoplasmic antibody; E-GPA, eosinophilic granulomatosis with polyangiitis; EULAR, European League Against Rheumatism; GPA, granulomatosis with polyangiitis; MPA, microscopic polyangiitis; MPO, microscopic polyangiitis; PAN, polyarteritis nodosa; P-ANCA, perinuclear antinuclear cytoplasmic antibody; PR3, proteinase 3.

particularly GPA. ${ }^{9,14}$ However, the results from the PEXIVA trial offer a different conclusion. In this study, there was no statistically significant difference in composite outcome of ESRD and death in patients receiving plasmapheresis versus the non-plasmapheresis group and also high-dose steroids versus reduced dose steroids. These emerging data from this important study are going to significantly impact the treatment guidelines in near future. ${ }^{25}$

Cyclophosphamide dosing usually begins at $0.7 \mathrm{~g} / \mathrm{m}^{2}$ of body surface area (BSA) and can be increased up to $1 \mathrm{~g} / \mathrm{m}^{2}$ of BSA) with the goal of obtaining remission, alternatively it can be dosed at $15 \mathrm{mg} / \mathrm{kg}$ as in the RAVE trial. ${ }^{26}$ Usually, the regimen is given once a month for 6 months, with leukopenia, anemia, thrombocytopenia, hemorrhagic cystitis, and infection usually being the dose-limiting side effects. ${ }^{26}$ It has been previously established that oral cyclophosphamide and IV pulse dose cyclophosphamide are equally effective with lower toxicity in the IV cyclophosphamide choice given exposure to lower levels of drug overall over the oral route. ${ }^{27}$ In non-rapidly progressing disease presenting with severe dialysis-requiring acute kidney injury or pulmonary hemorrhage, the Rituximab versus Cyclophosphamide in ANCA-associated renal vasculitis (RITUXVAS) trial showed that combining rituximab and cyclophosphamide together did not have a statistically significant positive impact on the induction of remission. ${ }^{28,29}$

Typically, in more indolent forms where severe AKI and RPGN are not part of the clinical picture of AAV, high-dose oral corticosteroids often with pulse dose steroids given intravenously for induction are required. It is usually required in patients with a need for greater than $20 \mathrm{mg}$ of prednisone to be placed on pneumocystis Jirvecki (PJP) prophylaxis.
This is usually accomplished with cotrimoxazole double strength three times a week. Alternative PJP prophylaxis can be accomplished with atovaquone $1,500 \mathrm{mg}$ daily (risk of hemolysis) and dapsone $100 \mathrm{mg}$ daily (risk of exacerbation of G6PD deficiency and hemolysis). Antihistamine blockers and proton pump inhibitors are usually also used to prevent stress ulcers, although new findings prompt concern with long-term proton pump inhibitor use, ${ }^{30,31}$ calcium and vitamin $\mathrm{D}$ are also usually given to prevent osteoporosis.

A new C5 inhibitor called avacopan has been postulated to interrupt C5a signaling (with its attendant function as a chemotactic agent and anaphylatoxin). Avacopan has been found to have extremely high rates of response when given concomitantly with standard rituximab or cyclophosphamide for induction of remission. This allows this agent to be given as a steroid-sparing agent, which may decrease metabolic, bone-related, ulcer-related events in patients who are poorly tolerant to high-dose steroids. ${ }^{32,33}$

In milder AAV, azathioprine can be used as an agent to allow induction of remission in mild non-organ-threatening disease, but most trials suggest its use as an agent for the maintenance of remission. ${ }^{34}$ Many other studies support using methotrexate in establishing remission if the vasculitis is not severe or rapidly progressive, although typically this agent is more often used in the maintenance of remission in AAV. ${ }^{14,27,35}$ Liver function tests must be monitored closely in patients on methotrexate, and risk of systemic toxicity increases with renal dysfunction. Table 2 describes the available regimens for induction of remission in AAV (with dosing) depending on the type of AAV and clinical presentation. 


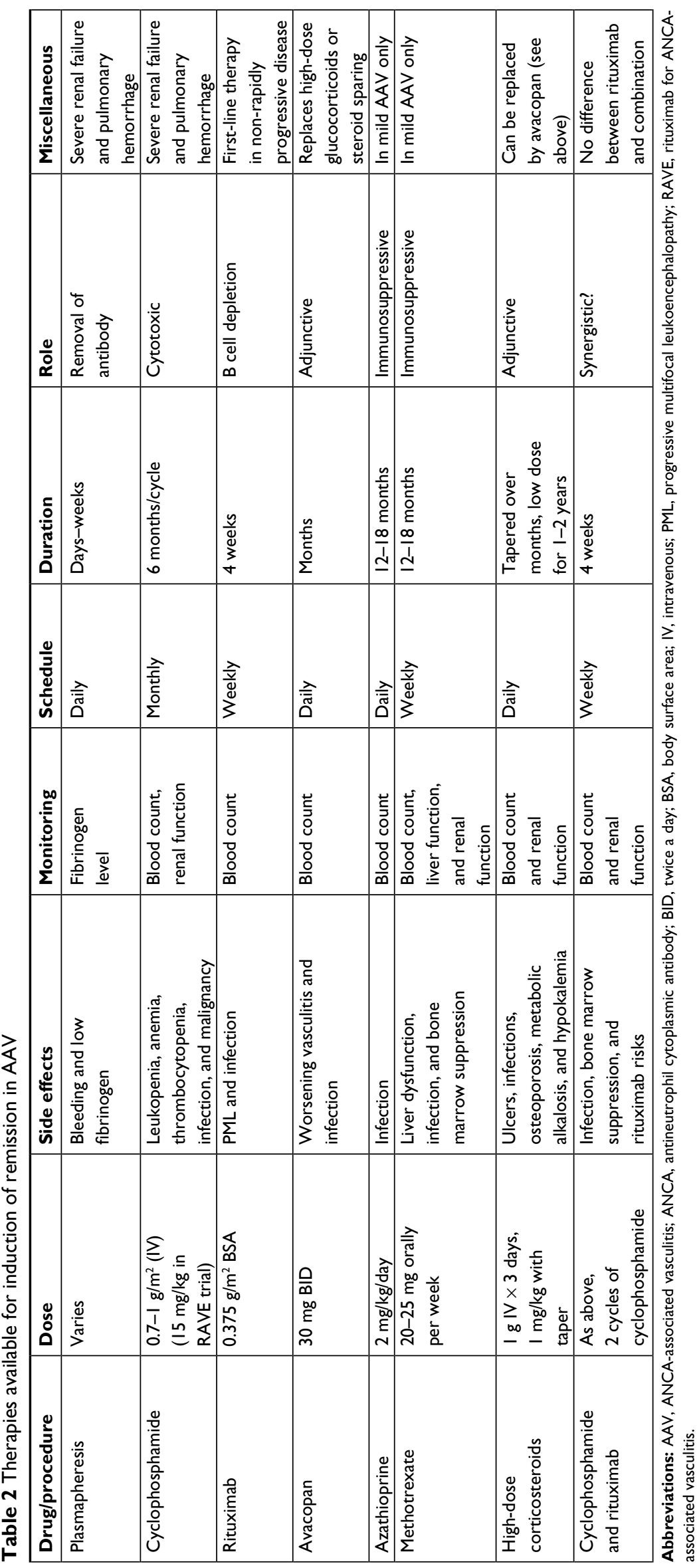




\section{Maintenance regimens}

The choices for the maintenance of remission, usually defined as normalization or stabilization of renal function, and decrease in proteinuria to $<0.5 \mathrm{~g} /$ day are similar to choices offered for induction of remission. The rituximab versus azathioprine as therapy for the maintenance of remission for antineutrophil cytoplasm antibody-associated vasculitis (RITAZAREM) showed that ongoing rituximab is also an even more effective option versus the established use of azathioprine for the maintenance of remission. ${ }^{34}$ Intermittent rituximab, given every 4 months, actually proved to be effective in refractory cases of AAV for the maintenance of an established remission. ${ }^{36}$

The superiority of azathioprine over mycophenolate mofetil has been demonstrated earlier. This was during the International Mycophenolate Mofetil Protocol to Reduce Outbreaks of Vasculitides (IMPROVE) study that failed to show mycophenolate as superior to azathioprine in remission maintenance in $\mathrm{AAV}^{37}$ In selected patients, for whom malignancy may be a concern, mycophenolate may still be an effective and safe option for the maintenance of remission. ${ }^{5}$

The use of methotrexate was discussed earlier and presents another popular option for remission maintenance. . $^{14,27,35}$ It is important to note that proteinuria control was inferior with the use of methotrexate compared to that of cyclophosphamide.$^{38}$ It is also important to note that both methotrexate and azathioprine had a $30 \%$ risk of relapse in 2 years and a similar risk of systemic adverse events. ${ }^{39}$ A summary of available agents and dosing for the maintenance of remission is shown in Table 1.

\section{Monitoring for possible relapse}

Relapse can be detected clinically through clinical signs (prodrome), hematuria, proteinuria, and serologically usually in the form of recurrent or persistent serological antibody markers for AAV. Importantly, the risk for relapse is about $30 \%$ for oral agents used for the maintenance of remission (such as azathioprine and methotrexate). ${ }^{39}$ The efficacy of rituximab allows for even better odds of sustained remis- sion, ${ }^{34,40}$ although at a downside of cost, risk (PML, infection), and need for an infusion center to deliver the drug every 4-6 months. Serial ANCA titers, especially if rising and if correlated with worsening renal function, are very concerning for a possible relapse. However, the results must be carefully interpreted since it seems that systemic, non-renal relapse is not associated with increased titers. ${ }^{41}$ Post-transplantation, $17 \%$ of the patients on calcineurins may experience an $\mathrm{AAV}^{42}$ Patients who have Alport's syndrome may experience an ANCA-like syndrome due to the formation of autoimmune antibodies against glomerular basement membrane proteins (Collagen alpha 4 a3,4 subunit). ${ }^{43}$

\section{Long-term monitoring for toxicity of patients who received immunosuppression}

In addition to the toxicity of corticosteroids, it is important to pay close attention to the possibility of developing JC virusinduced progressive multifocal leukoencephalopathy if they have been exposed to rituximab and any strong immunosuppressive agents (ie, calcineurins and cyclophosphamide). This condition should be suspected in case the patients develop any neurological abnormalities. Diagnosis can be made with brain MRI, CSF PCR, and ultimately, brain biopsy. The treatment is a clinical challenge since there is no effective antiviral therapy available. One suggested strategy is to decrease the immunosuppressive dose and maintain the treatment with steroids. ${ }^{44}$ In patients who have received cyclophosphamide, short term monitoring for hemorrhagic cystitis is recommended.$^{45}$ In long term monitoring, these patients are at increased risk for malignancies, particularly transitional cell cancer of the bladder.

\section{Conclusion}

AAVs are a heterogeneous group of severe conditions with a range of clinical presentations and complications. Early detection and treatment can lead to significantly better outcomes, especially preserving kidney function and avoiding renal replacement therapy. We reviewed the three most common types of AAVs along with pathology and treatment strategies.

Table 3 Therapies available for maintenance of remission in ANCA-associated vasculitis

\begin{tabular}{|l|l|l|l|}
\hline Drug/procedure & Dose & Schedule & Duration \\
\hline Cyclophosphamide & $\mathrm{I} \mathrm{mg} / \mathrm{kg}$ every 4-6 months & $4-6$ months & $\mathrm{I}-2$ years \\
\hline Rituximab & $\mathrm{I}$ g every 4 months & 4 months & $\mathrm{I}-2$ years \\
\hline Azathioprine & $2 \mathrm{mg} / \mathrm{kg} /$ day & Daily & $\mathrm{I}-\mathrm{I}$ months \\
\hline Methotrexate & $20-25 \mathrm{mg}$ orally per week & Weekly & $\mathrm{I}-\mathrm{I}$ months \\
\hline High-dose corticosteroids & $\mathrm{I} \mathrm{mg} / \mathrm{kg}$ with taper & Daily & $\mathrm{I}-2$ years \\
\hline Mycophenolate mofetil & $\mathrm{I}$ g oral BID & Daily & $\mathrm{I}-2$ years \\
\hline
\end{tabular}

Abbreviations: ANCA, antineutrophil cytoplasmic antibody; BID, twice a day. 
Despite severe adverse effects associated with the treatment, immunosuppressive therapies remain the best option in decreasing the complications and improving the outcomes.

\section{Author contributions}

Farid Arman co-wrote the manuscript; Marina Barsoum did the literature review and edited the manuscript; Hania Shakeri edited the molecular pathogenesis section as the pathologist; Umut Selamet, Olivia Wassef, Mira Mikhail, and Anjay Rastogi edited the text; Ramy M Hanna was an invited author who planned the review, wrote the manuscript, and was in charge of final editing. All authors contributed to data analysis, drafting and revising the article, gave final approval of the version to be published, and agree to be accountable for all aspects of the work.

\section{Disclosure}

The authors report no conflicts of interest in this work.

\section{References}

1. Hauschild S, Schmitt WH, Csernok E, Flesch BK, Rautmann A, Gross WL. ANCA in systemic vasculitides, collagen vascular diseases, rheumatic disorders and inflammatory bowel diseases. Adv Exp Med Biol. 1993;336:245-251.

2. Yates M, Watts R. ANCA-associated vasculitis. Clin Med. 2017;17(1):60-64.

3. Watts RA, Mooney J, Skinner J, Scott DG, Macgregor AJ. The contrasting epidemiology of granulomatosis with polyangiitis (Wegener's) and microscopic polyangiitis. Rheumatology. 2012;51(5):926-931.

4. Mahr A, Heijl C, Le Guenno G, Faurschou M. ANCA-associated vasculitis and malignancy: current evidence for cause and consequence relationships. Best Pract Res Clin Rheumatol. 2013;27(1):45-56.

5. Hanna RM, So N, Kaldas M, et al. Case report: patient with hepatitis C, p-ANCA, and cryoglobulin antibodies presenting with necrotizing crescentic p-ANCA glomerulonephritis. Case Rep Nephrol Dial. 2018;8(2):161-170.

6. Morita S, Ueda Y, Eguchi K. Anti-thyroid drug-induced ANCAassociated vasculitis: a case report and review of the literature. Endocr J. 2000;47(4):467-470.

7. Gioffredi A, Maritati F, Oliva E, Buzio C. Eosinophilic granulomatosis with polyangiitis: an overview. Front Immunol. 2014;5:549.

8. Perico N, Cattaneo D, Bikbov B, Remuzzi G. Hepatitis C infection and chronic renal diseases. Clin J Am Soc Nephrol. 2009;4(1):207-220.

9. Ter Maaten JC, Franssen CF, Gans RO, van Schijndel RJ, Hoorntje SJ. Respiratory failure in ANCA-associated vasculitis. Chest. 1996;110(2):357-362.

10. Hewins P, Morgan MD, Holden N, et al. IL-18 is upregulated in the kidney and primes neutrophil responsiveness in ANCA-associated vasculitis. Kidney Int. 2006;69(3):605-615.

11. Hanna RM, Lopez E, Wilson J. Granulomatosis with polyangiitis with myocarditis and ventricular tachycardia. Case Rep Med. 2017;2017:6501738-6.

12. Shahedi K, Hanna RM, Melamed O, Wilson J. Wegener's granulomatosis mimicking inflammatory bowel disease and presenting with chronic enteritis. Int Med Case Rep J. 2013;6:65-69.

13. Selamet U, Kovaliv YB, Savage CO, Harper L. ANCA-associated vasculitis: new options beyond steroids and cytotoxic drugs. Expert Opin Investig Drugs. 2007;16(5):689-703.
14. Hamour S, Salama AD, Pusey CD. Management of ANCA-associated vasculitis: Current trends and future prospects. Ther Clin Risk Manag. 2010;6:253-264.

15. Serratrice J, Chiche L, Dussol B, et al. Sequential development of perinuclear ANCA-associated vasculitis and anti-glomerular basement membrane glomerulonephritis. Am J Kidney Dis. 2004;43(3):e14.1-e14.5.

16. Westman KW, Selga D, Isberg PE, Bladström A, Olsson H. High proteinase 3-anti-neutrophil cytoplasmic antibody (ANCA) level measured by the capture enzyme-linked immunosorbent assay method is associated with decreased patient survival in ANCA-associated vasculitis with renal involvement. J Am Soc Nephrol. 2003;14(11):2926-2933.

17. Elgueta S, Larrea LR, Vargas D, Wurmann P, Goecke I. AB0590 performance of 2017 ACR/EULAR provisional classification criteria for granulomatosis with polyangiitis in chilean population. Annals of the Rheumatic Diseases. 2017;76(Suppl 2):1257-1258.

18. Flossmann O, Berden A, de Groot K, et al. Long-term patient survival in ANCA-associated vasculitis. Ann Rheum Dis. 2011;70(3):488-494.

19. Santos YA, Silva BR, Lira PN, et al. Eosinophilic granulomatosis with polyangiitis (formerly known as Churg-Strauss syndrome) as a differential diagnosis of hypereosinophilic syndromes. Respir Med Case Rep. 2017;21:1-6.

20. Chung SA, Seo P. Microscopic polyangiitis. Rheum Dis Clin North Am. 2010;36(3):545-558.

21. Jayne DR, Lockwood CM. Pooled intravenous immunoglobulin in the management of systemic vasculitis. Adv Exp Med Biol. 1993;336:469-472.

22. Stone JH, Merkel PA, Spiera R, et al. Rituximab versus cyclophosphamide for ANCA-associated vasculitis. N Engl J Med. 2010;363(3):221-232.

23. Specks U, Merkel PA, Seo P, et al. Efficacy of remission-induction regimens for ANCA-associated vasculitis. N Engl J Med. 2013;369(5):417-427.

24. Walsh M, Casian A, Flossmann O, et al. Long-term follow-up of patients with severe ANCA-associated vasculitis comparing plasma exchange to intravenous methylprednisolone treatment is unclear. Kidney Int. 2013;84(2):397-402.

25. Walsh M. Late breaking clinical trials. ERA-EDTA Daily Congress News letter. 2018;3:1.

26. Langford CA. Cyclophosphamide as induction therapy for Wegener's granulomatosis and microscopic polyangiitis. Clin Exp Immunol. 2011;164 Suppl 1:31-34.

27. de Groot K, Harper L, Jayne DR, et al. Pulse versus daily oral cyclophosphamide for induction of remission in antineutrophil cytoplasmic antibody-associated vasculitis: a randomized trial. Ann Intern Med. 2009;150(10):670-680.

28. Jones RB, Furuta S, Tervaert JW, et al. Rituximab versus cyclophosphamide in ANCA-associated renal vasculitis: 2-year results of a randomised trial. Ann Rheum Dis. 2015;74(6):1178-1182.

29. Jones RB, Tervaert JW, Hauser T, et al. Rituximab versus cyclophosphamide in ANCA-associated renal vasculitis. $N$ Engl J Med. 2010;363(3):211-220.

30. Xie Y, Bowe B, Li T, Xian H, Balasubramanian S, Al-Aly Z. Proton pump inhibitors and risk of incident CKD and progression to ESRD. $J$ Am Soc Nephrol. 2016;27(10):3153-3163.

31. Xie Y, Bowe B, Li T, Xian H, Yan Y, Al-Aly Z. Long-term kidney outcomes among users of proton pump inhibitors without intervening acute kidney injury. Kidney Int. 2017;91(6):1482-1494.

32. Tesar V, Hruskova Z. Avacopan in the treatment of ANCA-associated vasculitis. Expert Opin Investig Drugs. 2018;27(5):491-496.

33. Jayne DRW, Bruchfeld AN, Harper L, et al. Randomized trial of C5a receptor inhibitor avacopan in ANCA-associated vasculitis. J Am Soc Nephrol. 2017;28(9):2756-2767.

34. Gopaluni S, Smith RM, Lewin M, et al. Rituximab versus azathioprine as therapy for maintenance of remission for anti-neutrophil cytoplasm antibody-associated vasculitis (RITAZAREM): study protocol for a randomized controlled trial. Trials. 2017;18(1):112.

35. Ozaki S. ANCA-associated vasculitis: diagnostic and therapeutic strategy. Allergol Int. 2007;56(2):87-96. 
36. Alberici F, Smith RM, Jones RB, et al. Long-term follow-up of patients who received repeat-dose rituximab as maintenance therapy for ANCAassociated vasculitis. Rheumatology. 2015;54(7):1153-1160.

37. Hiemstra TF, Walsh M, Mahr A, et al. Mycophenolate mofetil vs azathioprine for remission maintenance in antineutrophil cytoplasmic antibody-associated vasculitis: a randomized controlled trial. JAMA. 2010;304(21):2381-2388.

38. Maritati F, Alberici F, Oliva E, et al. Methotrexate versus cyclophosphamide for remission maintenance in ANCA-associated vasculitis: A randomised trial. PLoS One. 2017;12(10):e0185880.

39. Pagnoux C, Mahr A, Hamidou MA, et al. Azathioprine or methotrexate maintenance for ANCA-associated vasculitis. $N$ Engl J Med 2008;359(26):2790-2803.

40. Guillevin L, Pagnoux C, Karras A, et al. Rituximab versus azathioprine for maintenance in ANCA-associated vasculitis. $N$ Engl J Med. 2014;371(19):1771-1780.
41. Han WK, Choi HK, Roth RM, Mccluskey RT, Niles JL. Serial ANCA titers: useful tool for prevention of relapses in ANCA-associated vasculitis. Kidney Int. 2003;63(3):1079-1085.

42. Nachman PH, Segelmark M, Westman K, et al. Recurrent ANCA-associated small vessel vasculitis after transplantation: A pooled analysis. Kidney Int. 1999;56(4):1544-1550.

43. Browne G, Brown PA, Tomson CR, et al. Retransplantation in Alport post-transplant anti-GBM disease. Kidney Int. 2004;65(2) 675-681.

44. Sanders JS, Riezebos-Brilman A, Homan van der Heide JJ. Progressive multifocal leuko-encephalopathy after ABO-incompatible kidney transplantation. Transpl Int. 2012;25(9):e104-e105.

45. Calatroni M, Buzio C, Vaglio A. The evolving paradigm of cancer risk related to cyclophosphamide therapy in granulomatosis with polyangiitis. Rheumatology. 2015;54(8):1339-1341.
The International Journal of Nephrology and Renovascular Disease is an international, peer-reviewed open access journal focusing on the pathophysiology of the kidney and vascular supply. Epidemiology, screening, diagnosis, and treatment interventions are covered as well as basic science, biochemical and immunological studies. The manuscript management system is completely online and includes a very quick and fair peer-review system, which is all easy to use. Visit http://www. dovepress.com/testimonials.php to read real quotes from published authors.

Submit your manuscript here: https://www.dovepress.com/international-journal-of-nephrology-and-renovascular-disease-journal 